\title{
RECQL4 wt Allele
}

National Cancer Institute

\section{Source}

National Cancer Institute. RECQL4 wt Allele. NCI Thesaurus. Code C49409.

Human RECQL4 wild-type allele is located in the vicinity of 8q24.3 and is approximately 6 $\mathrm{kb}$ in length. This allele, which encodes ATP-dependent DNA helicase Q4 protein, is involved in the initiation of DNA replication, cohesion of sister chromatids and maintenance of genomic stability. Certain allelic variants of the RECQL4 gene cause Rothmund-Thomson syndrome and RAPADILINO syndrome. 